\title{
EL PATRIMONIO AGRARIO: DEFINICIÓN, CARACTERIZACIÓN Y REPRESENTATIVIDAD EN EL ÁMBITO DE LA UNESCO
}

\author{
José Castillo Ruiz \\ Celia Martínez Yáñez \\ Departamento de Historia del Arte. Universidad de Granada \\ jcastill@ugr.es, celiamarya@ugr.es
}

\section{RESUMEN}

Este artículo pretende ofrecer una visión global de la incipiente protección de los bienes culturales generados por la actividad agraria a lo largo de la historia y reflexionar sobre los valores, tipos de bienes y principios que deberían guiar su tratamiento como una masa patrimonial unitaria. Para ello, analiza el grado de representación geográfica, temática y tipológica de los bienes del Patrimonio Agrario en la Lista del Patrimonio Mundial y la Lista Representativa del Patrimonio Cultural Inmaterial, profundiza en las causas que justifican el estudio del Patrimonio Agrario como un patrimonio específico de verdadera relevancia universal (al margen del éxito o no de su inscripción en ambos listados), expone y cuestiona diferentes aspectos que dificultan su correcta protección y propone los criterios y principios fundamentales para mejorar el reconocimiento y la sensibilización internacional sobre sus valores.

Palabras clave: Patrimonio Cultural y Natural; Patrimonio Agrario; UNESCO; Lista del Patrimonio Mundial; Lista Representativa del Patrimonio Cultural Inmaterial.

\begin{abstract}
The aim of this is offering a comprehensive vision on the emerging international recognition of heritage properties generated by agricultural and livestock rearing practices through history. It also reflects on the values, types of properties and principles that should guide their protection as a unitary heritage category. To do so, the paper analyzes the degree of representation of
\end{abstract}

Fecha de recepción: octubre 2012.

Fecha de aceptación: julio 2013. 
agrarian heritage properties on the UNESCO World Heritage List and Representative List of Intangible Heritage from a geographical, typological and thematic perspective. It also delves into the reasons for the study of the Agrarian Heritage as a specific heritage of a truly universal significance (regardless the success of its inscription on both lists), questions several aspects that hinder its identification and protection and sets out the main principles and criteria for improving international awareness and recognition of its values.

Key words: Cultural and Natural Heritage; Agrarian Heritage; UNESCO; World Heritage List; Representative List of Intangible Heritage.

\section{INTRODUCCIÓN}

En este artículo queremos dar a conocer algunos de los resultados del proyecto de investigación I+D+i, todavía en fase de desarrollo, financiado por el Ministerio de Economía y Competitividad de España (HAR2010 15809), denominado Proyecto PAGO (El Patrimonio Agrario. La construcción cultural del territorio a través de la actividad agraria $)^{1}$. En él, un amplio equipo interdisciplinar (Historia del Arte, Arquitectura, Geografía, Antropología, Ingeniería Agrícola, Ciencias Ambientales, Historia, Economía y Gestión Cultural) desarrolla diferentes líneas de investigación (http://www.patrimonioagrario.es/pago/PRESENTACION.html), sobre la dimensión cultural de los bienes agrícolas y ganaderos con el objetivo de proponer a la comunidad internacional el reconocimiento de una nueva categoría patrimonial, el Patrimonio Agrario.

De forma concreta, en este texto, vamos a exponer los resultados y conclusiones principales referidas a la línea de investigación El patrimonio Agrario en el marco de la UNESCO. Patrimonio Mundial y Patrimonio Cultural Inmaterial de la Humanidad, de la que somos responsables los dos investigadores firmantes de este artículo. No obstante, para conocer adecuadamente esto debemos establecer previamente cuáles son los principios que, según los resultados preliminares del Proyecto PAGO, conforman el Patrimonio Agrario, en lo referido a su definición, caracterización, protección y gestión.

\section{EL PATRIMONIO AGRARIO COMO NUEVO TIPO DE BIEN CULTURAL}

\subsection{Motivos para el reconocimiento del Patrimonio Agrario como nuevo tipo de bien cultural}

Le evolución experimentada por el concepto de Patrimonio Cultural en los últimos años ha permitido que nuevos tipos de bienes (el patrimonio industrial, el patrimonio del movimiento moderno o el patrimonio audiovisual,) hayan adquirido un reconocimiento y tratamiento diferenciado (Martínez, 2011). Esto ha permitido mejorar sustancialmente su caracterización y protección. El objetivo de nuestro proyecto es conseguir que también el Patrimonio Agrario consiga este tratamiento diferenciado. Esto significaría incluir el valor agrario (al igual que ha sucedido con otros como el industrial, paisajístico, identitario, inmaterial o contemporáneo) como uno de los valores a proteger por la legislación de Patrimonio Cultural.

1 Investigador Principal: José Castillo Ruiz. Profesor Titular del Departamento de Historia del Arte de la Universidad de Granada. 
Identificar el Patrimonio Agrario no significaría solamente incluir en la legislación sobre Patrimonio Cultural un nuevo valor a proteger, el agrario, sino que supondría incorporar una nueva forma de reconocer y agrupar los bienes culturales. Hasta ahora esta agrupación se hace o por el valor del bien (arqueológico, histórico, paleontológico....) o por su pertenencia a un espacio unitario (paisaje cultural, itinerario cultural, conjunto histórico, etc.). En el caso del Patrimonio Agrario, el elemento que permite agrupar a los bienes es, sin embargo, la actividad humana, en concreto la actividad agrícola y ganadera. Por esta razón, como ahora explicaremos, debemos considerar al Patrimonio Agrario de forma similar al Patrimonio inmaterial $^{2}$.

Con el reconocimiento de este nuevo tipo o categoría de Patrimonio se conseguirían los siguientes objetivos:

- El principal, la apreciación y el respeto de los bienes generados por la actividad agraria a través de la historia. Estos bienes, si bien disponen de valores de enorme importancia para todas las personas, apenas si tienen consideración social e institucional. Para avanzar en este reconocimiento debemos conseguir asociar aquellos contenidos de modernidad, progreso y solidaridad que existen en muchos ámbitos de lo agrario (la alimentación como derecho fundamental del hombre, diversidad biológica y cultural, desarrollo sostenible, calidad de vida, soberanía y seguridad alimentaria, agricultura ecológica y agroecología, etc.) a la propia actividad agraria y, sobre todo, a los agricultores y ganaderos, acabando con la visión peyorativa de los mismos que hay en muchos países (subdesarrollo, incultura, atraso o bajo nivel social).

- La posibilidad de conectar las iniciativas de valoración puestas en marcha por instituciones de diferentes ámbitos relacionadas con la agricultura y la ganadería (Agricultura, Alimentación, Medio Ambiente, Patrimonio Cultural, Patrimonio Natural...) y que en estos momentos están completamente incomunicadas, al menos en España. Especialmente importante es, en este sentido, superar la separación actualmente existente entre las dimensiones cultural, productiva, ambiental y biológica de la agricultura ${ }^{3}$.

- Independizar los bienes agrarios de otros tipos de bienes que hasta ahora se han apropiado de ellos y que están propiciando en gran medida su minusvaloración. Por ejemplo, del patrimonio industrial agroalimentario (donde los espacios agrarios son sólo el paisaje en el que se sitúan las fábricas), del patrimonio etnológico (donde lo agrario queda muy desdibujado dentro de la diversidad de actividades tradicionales prote-

2 Aunque no es el objeto de este trabajo, queremos señalar que la caracterización del Patrimonio Agrario que aquí hacemos se enmarca dentro de una tendencia futura del Patrimonio Cultural que hemos denominado la «patrimonalización del hombre» (Castillo Ruiz, 2007). Consiste en que el epicentro de la protección se está desplazando del objeto (sea material o inmaterial) al sujeto. Es decir, es la persona -individualmente o colectivamente- (sus actividades, sus creencias, sus intercambios...) la que se está convirtiendo cada vez más en el bien a proteger. Algunos ejemplos de lo expuesto son: los Tesoros Humanos Vivos, los Itinerarios Culturales o el Patrimonio Inmaterial.

3 Uno de los estudios de mayor interés que estamos realizando dentro del Proyecto PAGO es determinar la dimensión patrimonial de los cultivos que se producen en la Vega de Granada (habas, cebollas, patatas, alcachofas, tomates, etc.). Algunos de los aspectos estudiados en cada uno de los cultivos son: características organolépticas, cualidades paisajísticas, capacidad para generar patrimonio, valores simbólicos e identitarios, gastronomía, formas tradicionales de cultivo, trabajo generado... 
gidas) o del patrimonio rural $^{4}$ (se daría así cabida también a la agricultura urbana y periurbana).

- Permitir un adecuado tratamiento de los bienes agrarios en los mecanismos de protección del Patrimonio Cultural ya existentes: inclusión de los bienes agrarios en la declaración de las ciudades históricas (Figura 1) (también en palacios, monasterios u otras tipologías semejantes $)^{5}$, incorporación de los bienes y actividades agrarias en los catálogos de los planes urbanísticos y territoriales, evitar la desvinculación de los bienes declarados con la actividad agraria que le es consustancial, etc ${ }^{6}$.

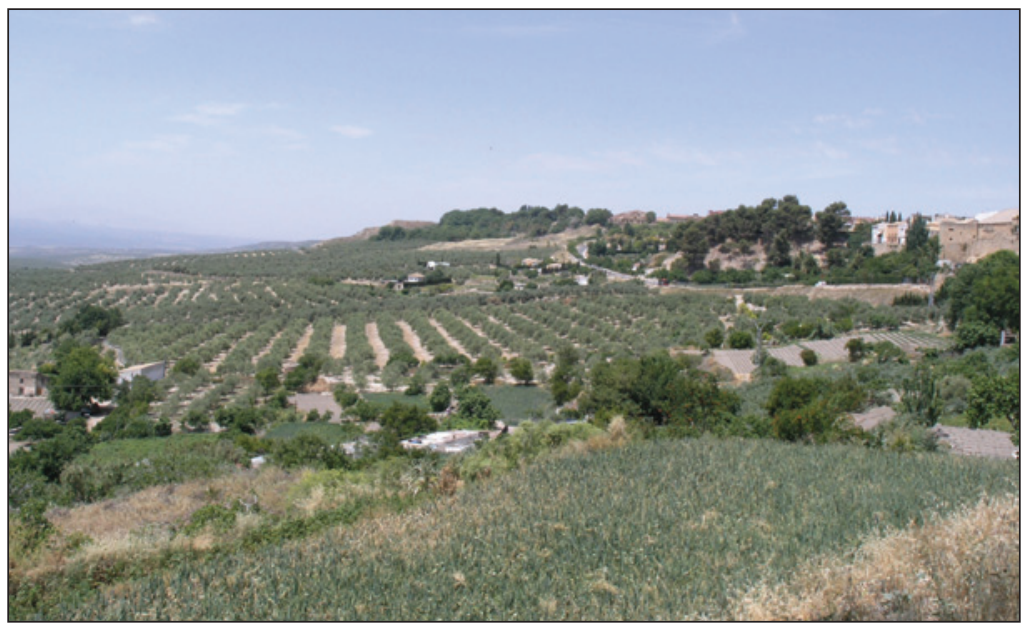

Autor: José Castillo Ruiz.

4 La diferencia entre el Patrimonio Agrario y el Rural (el cual además no existe formalmente como tipo de bien cultural) es que éste identifica al conjunto de bienes existentes en el medio rural, por lo que el elemento constitutivo principal es el territorio no urbano (en el cual tendrían cabida todos los bienes culturales generados por cualquier actividad, agraria o no, desarrollada sobre ese territorio), mientras que el patrimonio agrario es todo aquel (situado en el mundo rural, urbano o periurbano) generado o aprovechado por la actividad agraria (y sólo por esta actividad) a lo largo de la historia.

5 Este hecho, como puede verse en diversas ciudades españolas declaradas Patrimonio Mundial, como Úbeda y Baeza o Toledo, es una de las carencias más importantes en la protección del entorno y zonas de amortiguamiento -según la terminología de la UNESCO- de las ciudades históricas declaradas (Lalana Soto, 2010; Martin y Piatti, 2008). En relación a la consideración de los espacios agrarios en los Monumentos, un ejemplo que podemos considerar paradigmático a nivel internacional es la Alhambra de Granada, en la cual se han puesto en marcha diferentes proyectos para recuperar la actividad agraria en el Palacio del Generalife, entre ellas, la recuperación de las huertas musulmanas o la elaboración de aceite procedente de los olivos de la Dehesa del Generalife.

6 Al margen de los casos de Patrimonio Mundial a los que luego se hará referencia, un ejemplo al respecto sería el Palmeral de Orihuela (Alicante, España). Un espacio agrario declarado BIC donde la intervención sólo ha respetado las palmeras (esto denota una valoración exclusivamente ecológica de lo agrario, al entender las palmeras como una especie de bosque), construyendo en su interior (donde se desarrollaba la actividad agrícola) todo tipo de instalaciones deportivas, educativas o recreativas. 


\subsection{Definición y caracterización del Patrimonio Agrario.}

$\mathrm{Al}$ igual que sucede con otros patrimonios podemos hacer una definición del Patrimonio Agrario en función de los tipos de bienes relacionados con esta actividad productiva. Por ejemplo:

«... se entiende como patrimonio agrario todo aquel legado relacionado con la herencia histórica de la explotación agropecuaria, entendida ésta en un sentido amplio (áreas de cultivo, dehesas, pastizales, plantaciones forestales), bien sea de carácter material (paisajes, edificios relacionados con la producción y la transformación de los productos de la agricultura, infraestructuras y equipamientos agrarios, determinados tipos de hábitat rural...) o etnográfico (oficios, artesanías, folklore...).»(Silva, 2008).

Esta definición, al igual que sucede en otros tipos de patrimonios, nos lleva fundamentalmente a proteger bienes más o menos relevantes considerados singularmente (cortijos, por ejemplo en el caso español) o, en todo caso, ámbitos territoriales en los que los cultivos, (y no el conjunto de la actividad agraria) hayan conformado un paisaje estéticamente relevante. En ambos casos, reconocer estos elementos al margen de la actividad agraria que los ha generado resulta inadmisible, ya que, en la mayoría de los casos, son elementos utilitarios que cumplen una función concreta (producir alimentos, cobijar el ganado, organizar el riego, etc.), por lo que perderían gran parte de su valor una vez perdida esa función.

Podemos tomar como ejemplo la Vega de Granada (Cejudo y Castillo, 2010), un espacio agrario de gran valor cultural construido en el siglo XI y del que persiste todo el sistema estructural creado por los musulmanes en la Edad Media (trazado de las acequias, organización del riego, división de la tierra, etc.). Aunque en ella existen bienes materiales e inmateriales muy importantes (acequias, cortijos, secaderos, caminos, conocimientos tradicionales, etc.), si cada año los agricultores no construyeran, no engendraran, de nuevo la Vega sembrando y cultivando los diferentes productos, la Vega sería un erial salpicado de vestigios materiales inhertes. Esta «reinvención» de la Vega de Granada, en definitiva del Patrimonio Agrario, es semejante a la representación anual de un carnaval, procesión, fiesta..., por lo que la consideración y tratamiento que debemos dar al Patrimonio Agrario se asemeja, como decíamos, a la del Patrimonio Intangible.

De esta reflexión, debemos concluir que el elemento fundamental del Patrimonio Agrario, el que constituye su esencia patrimonial, es la actividad agraria. Por lo tanto, todos los aspectos que deben conformar su protección (definición, tipos de bienes que lo integran, categorías y figuras legales de protección, mecanismos de gestión y difusión) tienen que derivar de este principio fundamental: la identificación, valoración y preservación de la actividad agraria (Figura 2a y 2b).

Algunos de estos aspectos constitutivos del Patrimonio Agrario son los siguientes:

- El Patrimonio Agrario es el conjunto de bienes naturales y culturales, materiales e inmateriales, generados o aprovechados por la actividad agraria a lo largo de la historia. A partir de esta definición, el número y variedad de bienes que podemos identificar es enorme: bienes muebles (utensilios utilizados para el cultivo, transporte, almacenaje y manufactura de los cultivos); bienes inmuebles singulares (elementos constructivos con- 


\section{Figuras $2 \mathrm{a}$ y $2 \mathrm{~b}$}

LA VEGA DE GRANADA CULTIVADA Y LA VEGA DE GRANADA SIN CULTIVAR (ESPAÑA)
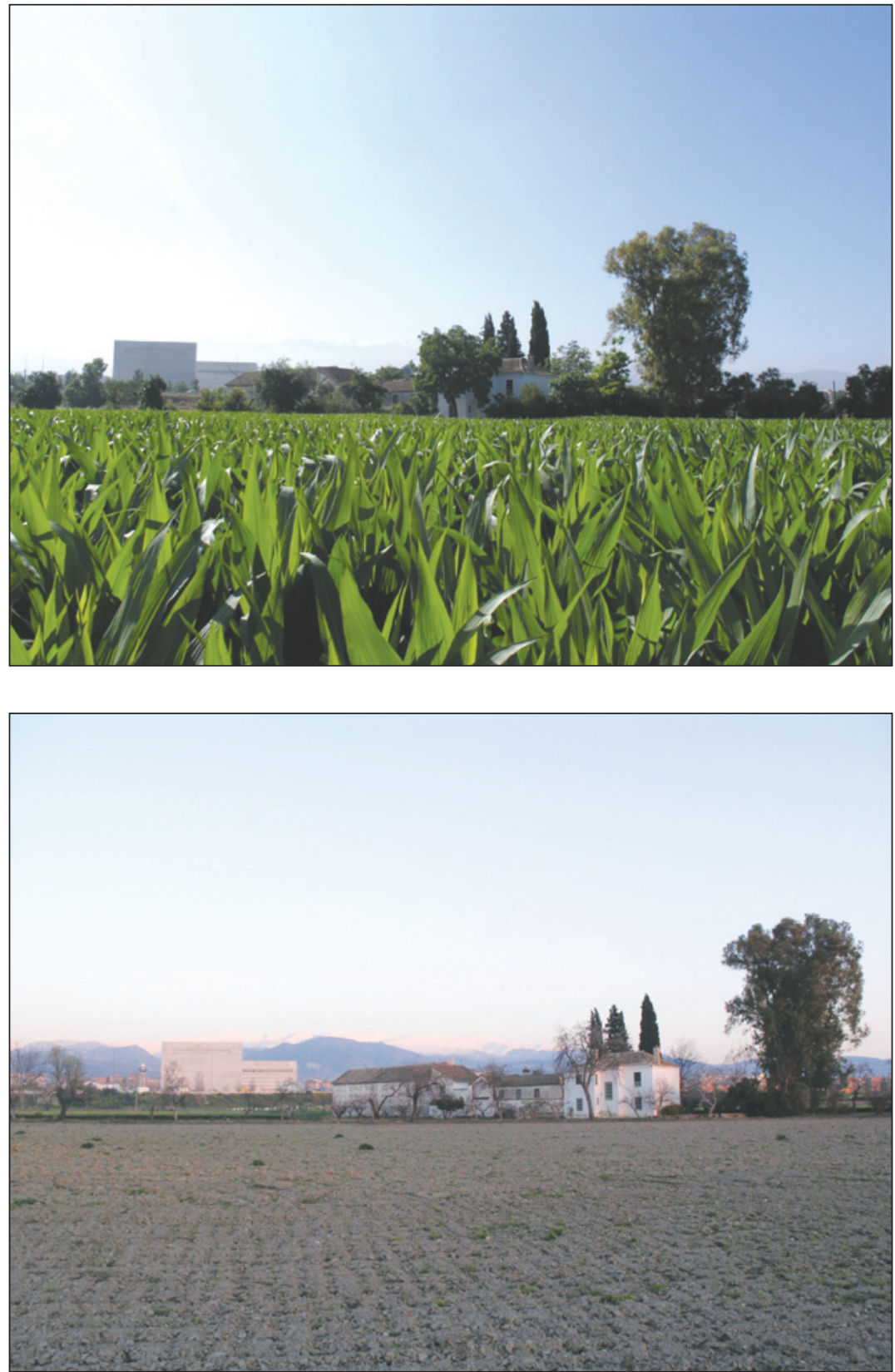

Autor: José Castillo Ruiz. 
siderados singularmente: cortijos, huertas, graneros, cercados, eras...); bienes inmuebles de conjunto (paisajes, sistemas de riego, agrosistemas singulares...); patrimonio inmaterial (creencias, rituales y actos festivos, conocimientos, gastronomía, técnicas artesanales...); patrimonio natural (variedades locales de cultivos, razas autóctonas de animales, semillas, suelos, vegetación y animales silvestres asociados...).

- La necesidad de valorar la actividad agraria desde una perspectiva histórica. Sólo de esta forma podemos diferenciar la actividad agraria de carácter patrimonial de aquella otra del presente (por ejemplo la agricultura ecológica) que también tienen valores muy relevantes y beneficiosos como el respecto al Medio Ambiente o el uso sostenible de los recursos naturales. Aquí aparecen cuestiones de gran interés como, por ejemplo, la continuidad histórica de la actividad (a través del concepto de tradicional) y su relación con los procesos de mecanización actuales.

- La actividad agraria no puede reconocerse y mantenerse en un solo bien, ni siquiera en un conjunto de ellos, sino que se manifiesta, se desarrolla en un ámbito territorial. Por esta razón, el procedimiento para identificar y preservar el Patrimonio Agrario debe ser de carácter territorial. Esto, unido a la dimensión funcional antes vista, plantea un importante problema patrimonial: cómo proceder a delimitar (lo cual resulta imprescindible para la protección) los espacios agrarios. A las dificultades propias que ya plantea la delimitación de cualquier bien intangible, debemos unir otras propias de la actividad agraria y ganadera: su amplitud y dispersión por el territorio, la variabilidad de los espacios agrarios en función de la explotación o no (temporal o definitiva) de los mismos o la interrelación con otras actividades, sobre todo en los ámbitos periurbanos. Para proceder a esa delimitación, los criterios que deberían seguirse serían fundamentalmente dos. El primero, constatar la dimensión histórica del espacio agrario a proteger y, el segundo, identificar aquellos elementos (geográficos o antrópicos) que dotan de unidad e identidad a dicho espacio: el sistema hidráulico creado para poner en producción un territorio, unidades geográficas, agrosistemas singulares, límites de propiedad de explotaciones agrarias singulares, etc.

- La protección jurídica de los bienes agrarios debe hacerse fundamentalmente a través de figuras de carácter territorial. En el caso español, al margen de la más utilizada a nivel internacional, la de paisaje cultural, la figura más adecuada es la de Zona Patrimonial (Verdugo, 2005), que aparece recogida en la legislación andaluza ${ }^{7}$. No obstante, nosotros proponemos la de Lugar de Interés Agrario. De esta forma se reconocería la singularidad de los bienes agrícolas y ganaderos.

- La protección del Patrimonio Agrario debe necesariamente ir vinculada a un sistema de gestión de carácter territorial que pueda afrontar todas las políticas necesarias para el mantenimiento y desarrollo de la actividad agraria (y todas aquellas otras que sean compatibles) en el espacio protegido.

Concluyendo lo expuesto hasta ahora, consideramos que el Patrimonio Agrario merece un tratamiento singular que permita reconocer adecuadamente los valores propios de los bienes agrícolas y ganaderos. En este sentido, los pasos dados por la UNESCO, con las carencias que ahora expondremos, en el reconocimiento sobre todo de paisajes culturales

7 Art. 26.8 de la Ley 14/2007, de 26 de noviembre, del Patrimonio Histórico de Andalucía. 
vinculados a lo agrario constituyen un importantísimo estímulo para avanzar en el análisis comparado e interdisciplinar de los bienes agrarios.

\section{RECONOCIMIENTO DEL PATRIMONIO AGRARIO EN AL ÁMBITO DE LA UNESCO: ESTADO DE LA CUESTIÓN Y RETOS FUTUROS}

\subsection{Estado de la cuestión y metodología}

El incipiente reconocimiento y protección internacional del Patrimonio Agrario se está llevando a cabo fundamentalmente en el contexto de las convenciones de la UNESCO sobre patrimonio cultural, material e inmaterial, es decir, la Convención sobre la Protección del Patrimonio Mundial Cultural y Natural (1972), y la Convención para la Salvaguardia del Patrimonio Cultural Inmaterial (2003), y mediante dos mecanismos diferentes:

- La inscripción de algunos de sus espacios y paisajes en la Lista del Patrimonio Mundial.

- La consideración de algunas manifestaciones intangibles de la actividad agraria dentro del concepto de patrimonio inmaterial, mediante su inscripción en la Lista Representativa del Patrimonio Cultural Inmaterial y la Lista del Patrimonio Inmaterial que requiere medidas de urgente salvaguardia.

Aunque ambos listados contienen bienes pertenecientes al Patrimonio Agrario, el estudio unitario de su caracterización y protección internacional resulta muy complejo, puesto que:

- El concepto de Patrimonio Agrario no existe como tal en las Convenciones de la UNESCO y sus correspondientes Directrices Prácticas, ni tampoco en la legislación internacional comparada, por lo que no partimos de una definición consensuada sobre los bienes que lo componen, ni sobre los criterios que emplean la UNESCO y sus organismos consultivos para evaluar su valor universal excepcional.

- Hasta la fecha, no se han llevado a cabo estudios globales sobre esta temática, limitándose los existentes al estudio específico de los paisajes de viñedos, los asociados con el pastoralismo y nomadismo y la arquitectura vernácula (UNESCO, 2001, 2007; ICOMOS, 2004; Cleere, 2004; Van Olst, 2006).

La línea de investigación El patrimonio Agrario en el marco de la UNESCO. Patrimonio Mundial y Patrimonio Cultural Inmaterial de la Humanidad del Proyecto PAGO trata de contribuir a la resolución de ambas carencias, por lo que los datos que ahora se publican son el resultado de una primera aproximación al estudio global de la protección del Patrimonio Agrario en el marco de la UNESCO, realizada analizando la escasa producción científica en la materia (Erickson, 2003; Martínez, 2010), así como todos los bienes incluidos en Lista del Patrimonio Mundial y Lista Representativa del Patrimonio Cultural Inmaterial en los que pueden reconocerse sus valores.

Dado que ninguno de estos listados permite hacer búsquedas temáticas o tipológicas, los resultados de esta investigación constituyen la primera identificación de los bienes de este patrimonio que tienen un reconocimiento internacional, que se verá enriquecida en el marco del proyecto $\mathrm{I}+\mathrm{D}$, base de este estudio. 


\subsection{La presencia del Patrimonio Agrario en la Lista del Patrimonio Mundial Cultural y Natural}

La protección internacional de algunos bienes materiales pertenecientes al Patrimonio Agrario es, en nuestra opinión, resultado de la toma de conciencia sobre la escasa representación de determinadas manifestaciones de la diversidad cultural en la Lista del Patrimonio Mundial.

Dicha toma de conciencia impulsó el lanzamiento de la Estrategia Global en la $18^{\text {a }}$ Sesión del Comité del Patrimonio Mundial (1994), con el objetivo de lograr una Lista del Patrimonio Mundial más creíble, representativa y equilibrada. Y ello porque, desde finales de los 80', era evidente:

- El predomino de determinadas tipologías del patrimonio cultural europeo:

- Sitios y conjuntos monumentales urbanos y arquitectónicos,

- Edificios religiosos del cristianismo,

- Ciudades históricas de Europa.

- La insuficiente representación de Asia, África, América Latina y Caribe y sus tipos específicos de bienes.

Para corregir estos desequilibrios el Consejo Internacional de Monumentos y Sitios (ICOMOS), como organismo consultivo de la UNESCO en lo referido al patrimonio cultural, realizó una aproximación - geográfica, temática, tipológica y cronológica- a los problemas de representatividad de la Lista del Patrimonio Mundial (Jokilehto et. al., 2005), designando determinados ámbitos temáticos que han permitido la identificación de nuevos bienes y valores susceptibles de poseer un valor universal excepcional e ingresar, en su caso, en la Lista del Patrimonio Mundial. Los directamente relacionados con el Patrimonio Agrario son los siguientes:

El bloque II.- «Creatividad y continuidad»-, que incluye:

a) Arquitectura de carácter agrícola (granjas, establos, silos, etc.)

b) Arquitectura industrial (fábricas, almacenes, gestión del agua, etc.)

c) Asentamientos rurales

d) Lugares sagrados (a menudo relacionados con la actividad agrícola en diversas regiones)

e) Paisajes culturales

El bloque IV. «Utilización de los recursos naturales»-, que incluye entre sus temas:

Agricultura y producción alimenticia:

1. Irrigación

2. Agricultura y ganadería

3. Pesca, caza y recolección

4. Y sus manufacturas

La práctica ausencia de bienes de este tipo inscritos hasta ese momento se ha solventado mediante la nominación de paisajes culturales, sitios mixtos, conjuntos de edificios, itinerarios culturales y bienes en serie relacionados con la actividad agraria, que analizaremos a continuación ${ }^{8}$.

8 La información sobre los bienes agrarios inscritos en la Lista del Patrimonio Mundial que se proporciona en los siguientes epígrafes ha sido extraída del expediente de inscripción (nominación) de cada uno de ellos. Todos los expedientes de inscripción de bienes inscritos en la Lista del Patrimonio Mundial, a partir de 1998, pueden consultarse en http://whc.unesco.org/en/list. Sin embargo, los correspondientes a nominaciones anteriores a esa fecha tan sólo están disponibles en el Centro de Documentación UNESCO-ICOMOS en Paris, que custodia toda la documentación original relativa a las inscripciones en la Lista del Patrimonio Mundial. 


\subsubsection{Paisajes Culturales vinculados a lo agrario}

Los paisajes culturales son la principal categoría conforme a la cual se declaran los bienes del Patrimonio Agrario en la Lista del Patrimonio Mundial. En nuestra opinión, ello se debe a dos cuestiones íntimamente relacionadas con la filosofía de protección inherente al concepto de paisaje cultural, que, a su vez, son fundamentales para el reconocimiento del valor patrimonial de determinados espacios agrarios:

- La toma de conciencia, hoy día ampliamente aceptada a nivel internacional, de que ya no existe la naturaleza en estado puro y de que todos los paisajes han sido transformados por la acción antrópica en mayor o menor grado.

- La especial importancia concedida a la transformación armoniosa del medio natural por parte del hombre y su relación con el concepto de desarrollo sostenible. Este reconocimiento es especialmente importante para la valoración de este patrimonio, al considerarse que la actividad agraria y sus formas tradicionales de hábitat y explotación de la tierra, son, en sí mismas, elementos fundamentales de la conservación y gestión de los paisajes culturales.

Los paisajes culturales que podríamos identificar como agrarios, o cuyos valores derivan en gran medida de esta actividad, inscritos hasta 2012 en la Lista del Patrimonio Mundial ascienden a 27 , proceden sobre todo del continente europeo y pertenecen en su mayoría a la tipología paisaje orgánicamente evolutivo y la subtipología de paisajes continuos.

El primer paisaje cultural de este tipo inscrito, en 1995, fue el de los Campos de Arrozales en Terrazas de las Cordilleras de Filipinas (Provincia de Ifugao, Isla de Luzón, y Región de Cordilleras) (Figura 3). Como ha señalado Cleere (2004), esta inscripción estableció un importante precedente para identificar la relevancia de los paisajes dedicados a la producción de alimentos básicos y cultivos de interés económico y, desde entonces, otros 26 paisajes relacionados con la actividad agraria han sido incluidos en la Lista del Patrimonio Mundial.

Figura 3

TERRAZAS DE ARROZALES DE LAS CORDILLERAS FILIPINAS EN LA ISLA DE LUZÓN

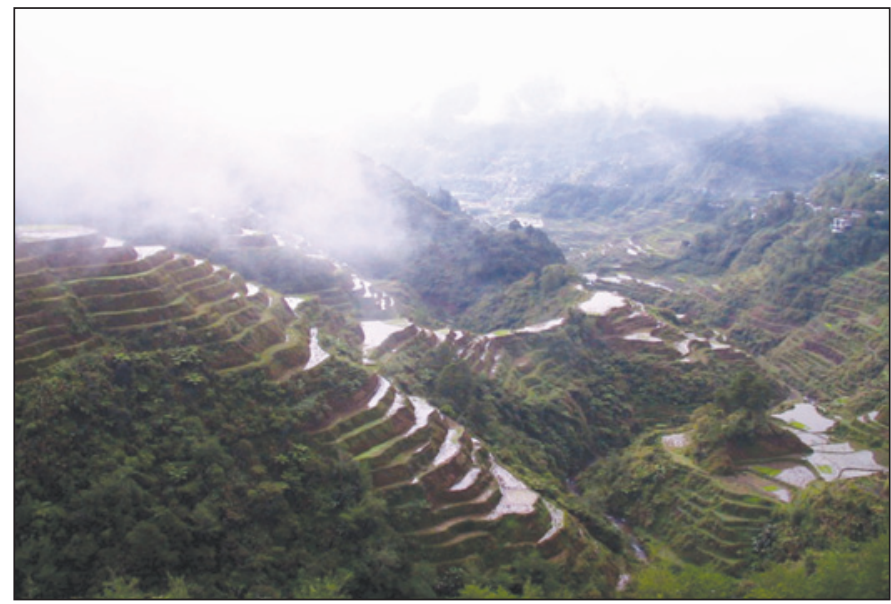

Autor: Yosomono Preetamrai Flickr Common Creatives. 
De acuerdo con nuestro análisis, pueden clasificarse en ocho grandes bloques temáticos y tipológicos:

_Paisajes de viñedos. Ascienden a seis y son los que han obtenido un mayor reconocimiento internacional, tanto por su representación en la Lista del Patrimonio Mundial como por los estudios monográficos que se les dedican: la Jurisdicción de Saint-Emilion (Francia, 1999), el Paisaje cultural de la Wachau (Austria, 2000), los paisajes de viñedos de Alto Douro e Isla del Pico (Portugal, 2001 y 2004, respectivamente), el Paisaje Histórico-Cultural de la región vinícola de Tojak (Hungría, 2002) y las Terrazas de Viñedos de Lavaux (Suiza, 2007).

_Cinco paisajes dedicados a otros cultivos de interés económico: El Valle de Viñales y el Paisaje Arqueológico de las Primeras Plantaciones Cafeteras en el Sureste de Cuba (1999 y 2000, respectivamente), el Paisaje de Agaves y Antiguas Instalaciones Industriales de Tequila (México, 2006) (Figura 4), la Llanura de Stari Grad (Croacia, 2008), asociada fundamentalmente al olivo, y el Paisaje Cultural Cafetero de Colombia (2011).

Figura 4

PAISAJE DE AGAVES Y ANTIGUAS INSTALACIONES INDUSTRIALES DE TEQUILA EN MÉXICO

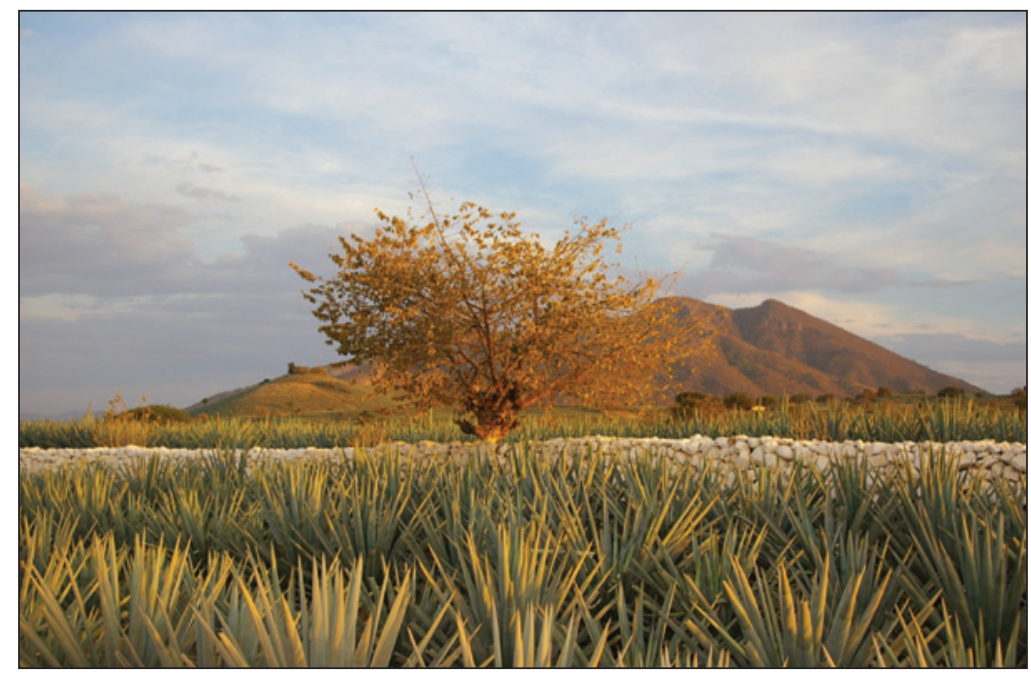

Autor: Thomassin Mickaël Flickr Common Creatives.

_Dos paisajes relacionados con la producción agraria básica (arroz, maíz, trigo, etc.): El ya mencionado Paisaje Cultural de los Campos de Arrozales en Terrazas (Filipinas, 1995) y el Paisaje Cultural de la Provincia de Bali: el Sistema Subak como testimonio de la Filosofía Tri Hita Karana, (Indonesia, 2012), compuesto por cinco terrazas de arrozales, abastecidas por un complejo sistema cooperativo de gestión del agua, y numerosos templos fuertemente asociados a las cosechas, y que, de acuerdo con su expediente de inscripción, es un testimonio excepcional de prácticas agrícolas igualitarias y sostenibles que han convertido a los balineses en los más prolíficos cultivadores de arroz de todo el archipiélago indonesio, a pesar del desafío que supone alimentar a una densísima población. 
_Tres paisajes de especial importancia por las infraestructuras y arquitectura vernácula asociadas a la actividad agraria: La Red de Molinos de Kinderdijk-Elshout (Holanda, 1997), el Palmeral de Elche (España, 2000), que ha mantenido el sistema de irrigación árabe original en condiciones tan buenas como para continúe en uso en nuestros días, y el mencionado Paisaje de Agaves y Antiguas Instalaciones Industriales de Tequila (México, 2006).

_Tres paisajes relacionados con la ganadería, la trashumancia, el pastoralismo y el nomadismo: El Paisaje Cultural del Valle de Orkhon (Mongolia, 2004), el Valle del Madriu-PerafitaClaror (Andorra, 2006) y el Paisaje Cultural y Botánico de Richtersveld (Sudáfrica, 2007).

_En estrecha relación con los anteriores, se han inscrito 2 paisajes fósiles que han mantenido en condiciones excepcionales testimonios de la actividad agraria desde al menos el neolítico: El Ecosistema y Paisaje Cultural Arcaico de Lopé-Okanda (Gabon, 2007), reconocido también como sitio mixto, y el Antiguo Sitio Agrícola de Kuk (Papua Nueva Guinea, 2008).

_Tres paisajes asociativos, cuyo valor universal reside en las tradiciones y creencias que se mantienen en los mismos y en su vinculación con las artes: El Valle del Orcia (Italia, 2004), en el que la actividad agraria ha producido un paisaje de particular belleza, recreada desde el Renacimiento por numerosos pintores (Figura 5); el Paisaje Cultural de Koutammakou, País de los Batammariba (Togo, 2004) y los Bosques Sagrados y Kayas de los Mijikenda (Kenya, 2008), donde la actividad agraria está asociada a las prácticas rituales de ambos pueblos, contribuyendo a la conservación y mantenimiento de su identidad cultural.

Figura 5

EL VALLE DEL ORCIA (ITALIA)

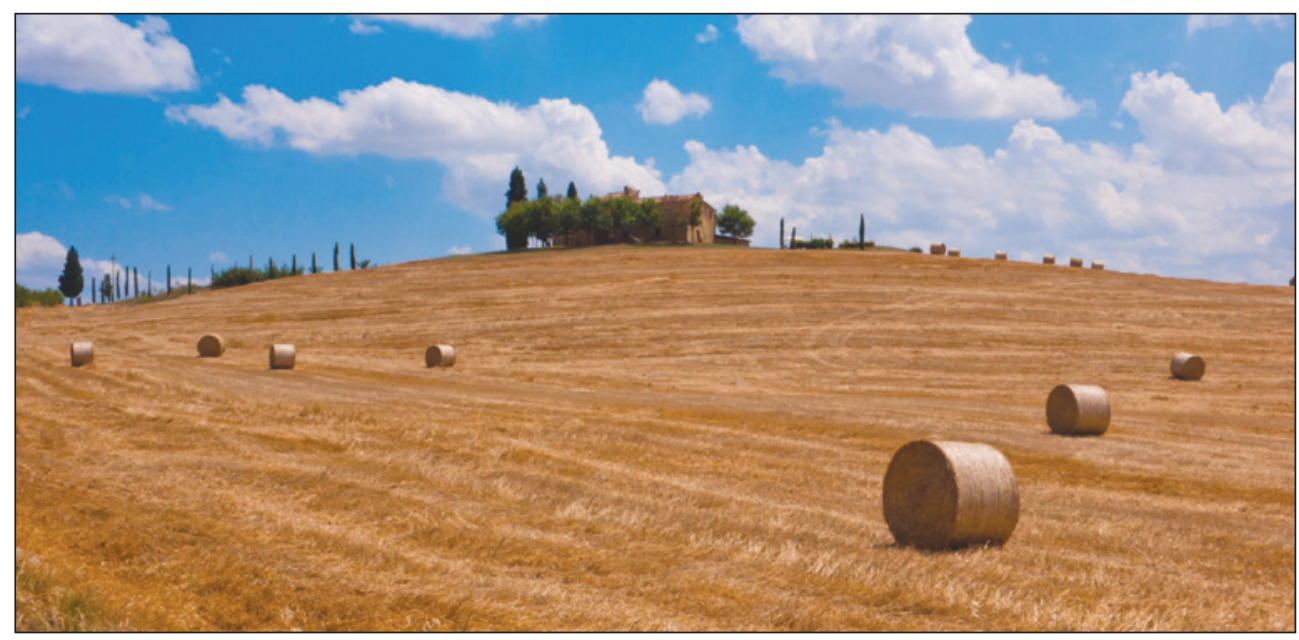

Autor: Guillem Pérez Flickr Common Creatives.

Cuatro paisajes relevantes por salvaguardar varios de estos valores: 1) La belleza escénica producida por los cultivos y los asentamientos y arquitectura vernácula asociados - caso de la Costa Amalfitana (Italia, 1997) y el Paisaje Agrario del Sur de la Isla de Öland (Suecia, 2000) -; 2) La presencia de cultivos agrarios básicos determinantes en la configuración y 
evolución del paisaje y de testimonios de sociedades seminomadas agropastorales y sus rituales sagrados - caso del Paisaje Cultural del País de Bassari: Bassari, Fula y Bedik (Senegal, 2012) -; 3) El caso particular del Paisaje Cultural de Grand Pré (Canadá, 2012), testimonio del desarrollo de la actividad agraria como consecuencia de la construcción de diques desde el siglo XVII, e inscrito, al igual que el anterior, también debido a su valor asociativo como memorial del modo de vida arcádico y su posterior deportación a partir de 1755, conocida como Grand Dérangement.

A pesar del hecho muy positivo que supone la creciente inscripción y protección internacional de espacios patrimoniales de este tipo, el análisis comparado de estas nominaciones revela un marcado desequilibrio geográfico en la representación de los paisajes culturales agrarios en la Lista del Patrimonio Mundial: 4 pertenecen al área de Asia Pacífico, 4 al área de América Latina y el Caribe, 5 al continente africano, y uno a Norteamérica, frente a los restantes 13 bienes procedentes exclusivamente del continente europeo, y sin que, hasta la fecha, se hayan incluido paisajes agrarios de los Países Árabes.

Algo similar sucede con la propia actividad agraria protegida a través de ellos, ya que, a pesar de las numerosas reuniones regionales organizadas por la $\mathrm{UNESCO}^{9}$ para hacer hincapié en la importancia de los paisajes relacionados con la producción agraria básica, la mayoría de los inscritos durante los últimos años se relacionan con cultivos de interés económico, y en particular con la producción de vino. Ello se explica, en parte, por el fuerte valor estético y paisajístico de estos cultivos, que siguen teniendo un extraordinario peso en el conjunto de la Convención como criterios de inscripción, y, sobre todo, por su importancia económica, que propicia su nominación por las naciones productoras, especialmente europeas.

\subsubsection{Otras tipologías}

Junto a los paisajes culturales, pero con una representatividad mucho menor, existen otras 4 categorías bajo las que se han inscrito bienes del Patrimonio Agrario en la Lista del Patrimonio Mundial: Sitio Mixto, Itinerario Cultural, Bienes en Serie y Conjunto de Edificios.

Los sitios mixtos aparecieron en las Directrices Prácticas para la Aplicación de la Convención de 1994, siendo reformulados en las de 1999, para inscribir a aquellos bienes y paisajes que presentan un valor universal excepcional tanto en relación con los criterios del patrimonio cultural (criterios i- vi) como en relación con los del patrimonio natural (criterios vii-x), el cual ha sido fehacientemente constatado en ambos casos. Esta doble constatación no es necesaria en los Paisajes Culturales, donde la relevancia de ambos valores radica en su integración y simbiosis, pero no en los valores culturales y naturales singularmente considerados.

En el caso del Patrimonio Agrario, esta especial importancia de los valores naturales y culturales se ha identificado en tres sitios mixtos:

- El Monte Perdido en Pirineos, un espectacular paisaje montañoso cuya nominación transfronteriza comparten Francia y España, y cuya inscripción en 1997 se debe, como también sucede en los siguientes ejemplos, tanto a sus valores exclusivamente relacionados con el patrimonio natural como a sus valores culturales asociados a la

9 Un listado de estas reuniones y sus contenidos principales puede consultarse en http://whc.unesco.org/en/ culturallandscape/\#3 
actividad agraria. Los valores naturales residen en que incluye dos cañones, los más grandes y profundos de Europa, situados en la vertiente meridional española, y tres grandes circos glaciares en la vertiente septentrional francesa. Por su parte, los valores culturales se justifican en el hecho de que Monte Perdido es también una zona de pastoreo donde se puede observar un modo de vida rural muy extendido antaño por las regiones montañosas de Europa, que sólo se ha conservado intacto en este lugar de los Pirineos, proporcionando un testimonio inestimable -formado por aldeas, granjas, campos, pastizales de altura y carreteras de montaña- del pasado agrario de la sociedad europea.

- La Región de Laponia (Suecia, 1996), una de las últimas y mayores regiones del mundo en la que predomina todavía un modo de vida ancestral, basado en la trashumancia estacional de los lapones y sus inmensos rebaños de renos a través de un bellísimo paisaje, cuyo valor universal excepcional reside también en la existencia de morrenas y cursos de agua glaciares ilustrativos de procesos geológicos antiguos y contemporáneos.

- El Ecosistema y Paisaje Cultural Arcaico de Lope Okanda (Gabón, 2007), que conserva las evidencias más antiguas (a partir del Neolítico) de la domesticación de plantas y animales y del uso de los recursos forestales por parte del hombre y es, además, un importantísimo refugio de grandes mamíferos en peligro de extinción.

En segundo lugar, la relevancia de la actividad agraria en el desarrollo humano e histórico también ha sido reconocida bajo la tipología de Itinerario Cultural. Esta tipología es sin duda la más compleja entre las que componen el concepto de Patrimonio Mundial y fue incluida en las Directrices Prácticas de 2005 para inscribir a las vías de comunicación, cuya existencia histórica y física puede comprobarse empíricamente, que han producido una interfecundación cultural, la cual ha generado bienes patrimoniales, tangibles e intangibles, a lo largo de su recorrido y del tiempo en que han sido utilizadas.

El único Itinerario Cultural de la Lista del Patrimonio Mundial cuyo valor universal excepcional está directamente relacionado con la actividad agraria es la Ruta del incienso -Ciudades del Desierto del Neguev (Israel)-. Fue inscrita en 2005, entre otras razones por conservar vestigios de sistemas de irrigación extremadamente perfeccionados, así como de construcciones que atestiguan cómo el hombre logró asentarse en estas tierras desérticas y desarrollar en ellas la agricultura y el comercio del incienso y la mirra.

Además, en julio de 2012 se ha inscrito en la Lista la primera nominación perteneciente a la categoría de Bienes en Serie, creada para incluir bienes pertenecientes al mismo grupo histórico-cultural o característicos de una zona geográfica, cuyo valor universal excepcional está directamente relacionado con el Patrimonio Agrario. Se trata de las Granjas de Hälsingland (Suecia), una selección de 7 casas rurales y sus edificios agrícolas asociados (entre otros de su misma tipología existentes en el área del bosque de Taiga), cuya extraordinaria y rica decoración refleja el punto más alto de prosperidad alcanzado por el paisaje agrícola en el siglo XIX y el estatus social de sus agricultores.

Por último, cabe señalar que existe un buen número de bienes inscritos en la Lista del Patrimonio Mundial, entre ellos Konso, Versalles, la Alhambra y el Generalife, el Paisaje Cultural de Aranjuez o Ubeda y Baeza, donde la actividad agraria y sus espacios han sido y/o son muy relevantes en la conformación y evolución de los espacios protegidos, así como en 
sus entornos y zonas de amortiguamiento, si bien no han sido convenientemente destacados en sus respectivas nominaciones como elementos consustanciales al valor universal excepcional y a su adecuada caracterización y conservación (Figura 6).

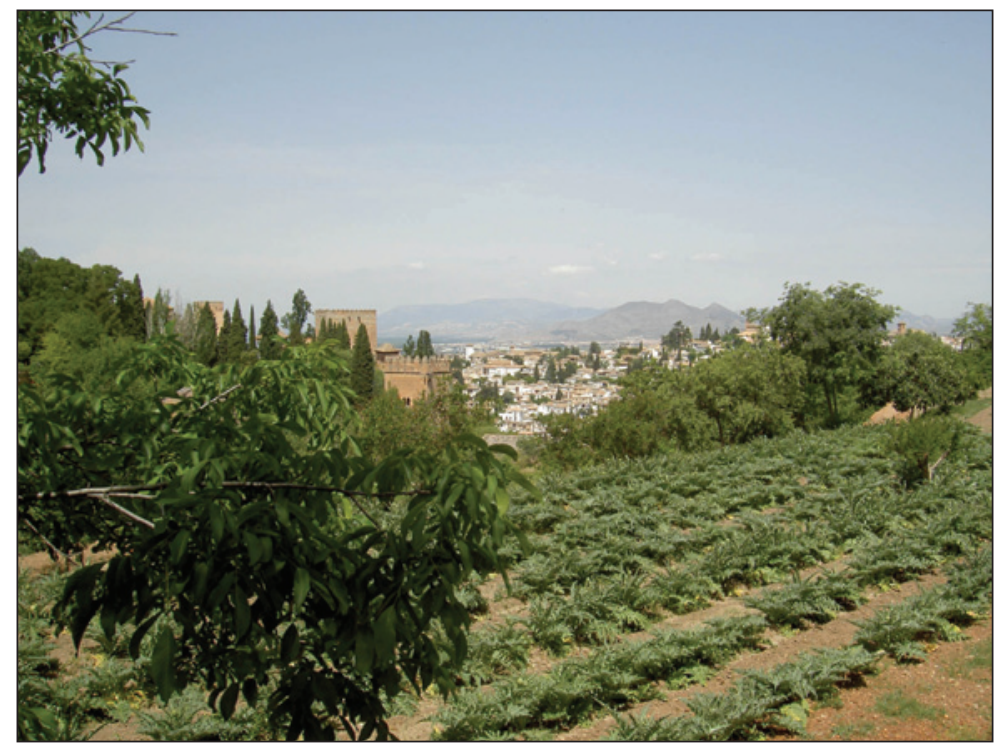

(C) Autor: José Castillo Ruiz

De hecho, la persistencia de un cierto olvido de lo agrario, especialmente en el ámbito urbano, es fácilmente constatable si tenemos en cuenta que sólo una nominación, Provins -Ciudad de Ferias Medieval- (Francia), inscrita como Conjunto de Edificios, reconoce el valor patrimonial de las actividades agrarias en dicho ámbito. Fue inscrita en 2001 por constituir un testimonio excepcional de la primera etapa del auge de las ferias comerciales internacionales vinculadas a la industria de la lana, que ha preservado su estructura urbana, especialmente concebida para dar acogida a dichas ferias y sus actividades conexas.

\subsection{El Patrimonio Agrario en la Lista Representativa del Patrimonio Cultural Inmaterial de la Humanidad}

El carácter intangible del patrimonio agrario engloba dos aspectos fundamentales:

- El propio patrimonio intangible, es decir, las tradiciones, ritos, conocimientos, etc., relacionados con la actividad agraria.

- El significado intangible presente en los bienes materiales del patrimonio agrario, cuya importancia y trascendencia no es siempre reconocida, aunque es fundamental para la conservación de la autenticidad de este patrimonio y la necesaria, y por ahora 
insuficiente, vinculación recíproca entre los valores inmateriales del patrimonio agrario y los espacios que son su soporte. La deficiente vinculación entre los espacios agrarios, su delimitación, y sus valores tangibles e intangibles es, en nuestra opinión, una de las mayores carencias que presenta la protección del Patrimonio Agrario en el marco de la UNESCO, visible, de hecho, en algunas de las nominaciones que analizamos en este epígrafe.

A partir de 2006, en que entró en vigor la Convención para la Salvaguardia del Patrimonio Cultural Inmaterial de 2003, el reconocimiento del Patrimonio Cultural Inmaterial se formaliza mediante la inscripción en la Lista Representativa del Patrimonio Cultural Inmaterial de la Humanidad y la Lista de Salvaguardia Urgente.

En el año $2011^{10}$ ambos listados sumaban 259 elementos, de los cuales tan sólo 24, aproximadamente, están directamente relacionados con la actividad agraria.

Estos 24 elementos ${ }^{11}$ pueden clasificarse en función de su pertenencia a los siguientes ámbitos reconocidos por la Convención:

_Usos Sociales, Rituales y Actos Festivos, que abarcan nueve elementos relacionados con lo agrario: El Hudhud, relatos cantados de los Ifugao Hudhud (Filipinas. Originalmente proclamado en 2001 e inscrito en 2008); el Akiu no Taue Odori y Oku-noto no Aenokoto (Japón, 2009), el Ganggangsullae (Republica de Corea, 2009), el rito Yeongdeunggut en Chilmeoridang (Isla de Cheju, Republica de Corea, 2009), el Desfile de la Máscara Ijele (Nigeria, 2009), la Danza de los campesinos del grupo étnico coreano de China (2009), los Krakelingen y el Tonnekensbrand, festividades del pan y del vino del final del invierno en Geraardsbergen (Bélgica, 2010) y el Mibu no Hana Taue, ritual del trasplante del arroz en Mibu, (Hiroshima, Japón, 2011).

Entre ellos nos interesa especialmente el El Hudhud, Relatos Cantados de los Ifugao en Filipinas, ya que podemos relacionarlo con el propio paisaje cultural inscrito en la Lista del Patrimonio Mundial, reflejando la indisoluble, aunque deficitariamente protegida, relación entre el patrimonio agrario tangible e intangible, y sobre todo, la interdependencia de ambos para su efectiva conservación. Consiste en una tradición de más de 200 cantos narrativos que practican fundamentalmente las mujeres durante la siembra y la cosecha del arroz, así como en los ritos fúnebres, reflejando la importancia de este cultivo. Sin embargo, y a pesar de su importante raigambre histórica y social, la transmisión futura del Hudhud plantea serias incertidumbres, debido, entre otras, a las siguientes razones: la escasez de testimonios escritos, la conversión de los Ifugao al catolicismo -que fragilizó la cultura tradicional y matriarcal asociada a los cantos-, su asociación a la cosecha manual del arroz -actualmente mecanizada- y el constante decrecimiento de sembradores -debida a la continua migración a las ciudades y las consecuencias del cambio climático-. Todo ello motivó la inclusión del mencionado paisaje cultural, soporte material de esta tradición, en la Lista del Patrimonio Mundial en Peligro entre 2001 y 2012 y el apoyo al Hudhud, su mayor manifestación intangible, mediante un programa de salvaguardia desarrollado entre 2003 y 2008.

10 La próxima reunión del Comité Intergubernamental para inscribir las candidaturas correspondientes al año 2012 tendrá lugar entre el 3 y 7 de diciembre de 2012 en la sede de la UNESCO en Paris.

11 La información sobre los bienes inscritos en la Lista Representativa del Patrimonio Cultural Inmaterial que se proporciona en este epígrafe ha sido extraída del expediente de inscripción (nominación) de cada uno de ellos y puede consultarse en http://www.unesco.org/culture/ich/index.php?lg=en\&pg=00011 
_Conocimientos y usos relacionados con la naturaleza y el universo. Engloban dos elementos directamente relacionados con la agricultura: Las Tradiciones y prácticas vinculadas a los Kayas en los Bosques Sagrados de los Mijikendas (Kenia, 2009), que, como vimos, también se han protegido mediante la inscripción de su paisaje cultural agrario en la Lista del Patrimonio Mundial; y los Tribunales de Regantes del Mediterráneo Español: El Consejo de Hombres Buenos de la Huerta de Murcia y el Tribunal de las Aguas de la Huerta de Valencia (España, 2009), dos instituciones jurídicas de gestión del agua y los cultivos cuyos orígenes se remontan a la época de Al Ándalus y siguen siendo reconocidas por el ordenamiento jurídico en vigor.

_Técnicas artesanales y prácticas tradicionales. Incluyen ocho elementos relacionados con la actividad agraria: La Tradición del Boyeo y las Carretas (Costa Rica, originalmente proclamada en 2005 e inscrita en 2008), la Sericultura y la Artesanía Chinas de la Seda (2009), la Técnica Japonesa de Fabricación de Tejido de Seda (2010), la Fabricación del Barkcloth en Uganda (2008), la Fabricación de tejidos Mosi en la región Hansan, el Jeju Chilmeoridang Yeongdeunggut (República de Corea, 2011), la Cetrería, una nominación transnacional entre Emiratos Árabes Unidos, Bélgica, República Checa, Francia, República de Corea, Mongolia, Marruecos, Qatar, Arabia Saudita, España, República Árabe y Siria inscrita en 2010 y la Equitación en la Tradición Francesa (2011) que, de acuerdo a su expediente de inscripción, es un ejemplo de coexistencia armoniosa y respeto entre hombres y animales y que, aunque no se vincule directamente con lo agrario supone, junto a la Cetrería, la única inscripción que reconoce expresamente el valor patrimonial de prácticas tradicionales vinculadas a los animales.

_La Gastronomía. Sin duda una de las manifestaciones más visibles e importantes del patrimonio agrario inmaterial, que ha sido reconocida, sólo a partir del año 2010, mediante la inscripción de 4 elementos, La Dieta Mediterránea (nominación transnacional entre España, Grecia, Italia y Marruecos, 2010), la Cocina Tradicional Mexicana, Cultura Comunitaria, Ancestral y Viva -El paradigma de Michoacán (2010)-, la Comida Gastronómica de los Franceses (2010) y la Tradición del Keşkek (Turquía, 2012), consistente en la preparación, por parte de hombres y mujeres, de una comida ceremonial a base de maíz y carne, el Ke kek, destinada a la celebración de actos solemnes como los matrimonios, circuncisiones y otras ceremonias religiosas.

Por último, tan sólo un bien, la Feria Invernal Anual y Mercado de Ganado en Sint-Lievens-Houtem (Bélgica, 2010), se relaciona específicamente con la ganadería.

\section{CONCLUSIONES}

Analizadas en sus aspectos principales las diferentes declaraciones realizadas por la UNESCO de los bienes relacionados con el Patrimonio Agrario, podemos extraer una serie de conclusiones, tomando como referencia los principios que fundamentan este concepto según el Proyecto PAGO. Son las siguientes:

- Es muy significativa la importancia otorgada por la UNESCO a los bienes agrarios, ya que a pesar de la novedad de este tipo de bienes son muchos los sitios inscritos relacionados con la actividad agraria. La razón tiene que ver con el hecho de que los bienes del patrimonio agrario pertenecen precisamente a las nuevas tipologías y ejes 
temáticos con los que se busca reequilibrar la representatividad temática, regional y tipológica de la Lista del Patrimonio Mundial.

- Sorprende el importante número de declaraciones existentes en los países desarrollados, lo que contrasta con el alto grado de industrialización de la agricultura en los mismos. Al margen de por motivos relacionadas con el tradicional eurocentrismo de la Lista, la razón tiene que ver con la necesidad de proteger aquellos espacios que todavía se mantienen con un alto grado de autenticidad e integridad y cuya desprotección podría provocar su destrucción o grave alteración. Esta situación de peligro no se produce tanto en los países en vías de desarrollo, donde apenas ha llegado la denominada Revolución Verde. Tampoco podemos obviar las razones que tienen que ver con la consecución de una marca de prestigio que permita una mayor comercialización del lugar.

- Predominio de los sitios relacionados con la vid. Si estos sitios los relacionamos con los del café y el agave (y en menor medida con el olivo) podemos extraer interesantes conclusiones:

- Aunque se trata de paisajes agrarios, los productos manufacturados extraídos de estos paisajes (el vino, el café, el tequila o el aceite) desempeñan un papel importante en la declaración. Esto significa que existe un alto interés por conseguir una marca de prestigio que ayude a la comercialización de estos productos. En algunos casos, la importancia otorgada a dichos productos puede producir que la actividad agraria pierda relevancia en la valoración del sitio.

- Existe un componente estético muy importante en estas declaraciones y, además, una visión del territorio ambientalista o ecológica. Esto significa que, en muchos casos, los sitios declarados son considerados más como un conjunto de plantas o arbustos (una especie de bosque) que como un paisaje resultado de una determinada forma de manejo agrario.

- Incipiente inclusión de bienes relacionados con la ganadería En nuestro proyecto de investigación hemos constatado como, dentro de la actividad agraria, existe una menor consideración hacia la ganadería y hacia los pastores, por lo que es muy importante el reconocimiento que empieza a prestar prestado por la UNESCO a esta actividad. No obstante, en la ganadería se valora mucho la dimensión territorial y natural, lo que nos lleva de nuevo a esa visión naturalista del territorio que subyace en las declaraciones analizadas.

- Inadecuada vinculación entre el patrimonio material e inmaterial. Consideramos que las declaraciones separadas de la dimensión inmaterial y material de un mismo bien (como sucede con los Campos de Arrozales en Terrazas de las Cordilleras de Filipinas y El Hudhud, Relatos Cantados de los Ifugao en Filipinas) puede ser contraproducente para la conservación unitaria del sitio. En este mismo sentido, consideramos inapropiadas las declaraciones de bienes inmateriales de forma independiente al espacio agrario al que están vinculados. Un ejemplo muy ilustrativo son los Tribunales de Regantes del Mediterráneo Español: El Consejo de Hombres Buenos de la Huerta de Murcia y el Tribunal de las Aguas de la Huerta de Valencia. En ambos casos, el bien protegido es la institución (con su indumentaria, ritos, lugar de celebración, etc.) que gestiona la distribución del agua en la Huerta murciana y valenciana. Estas huertas están en la 
actualidad desprotegidas y en peligro de desaparecer, por lo que si al final se destruyen los Tribunales se convertirán en una falsa representación teatral sin contenido real.

- Importancia creciente de la gastronomía. La relevancia que significa reconocer el valor cultural de la cocina de los diferentes países pierde valor si tenemos en cuenta que estas declaraciones se quedan en la mayoría de los casos en simples reconocimientos y, en otros casos, se corresponden con estrategias para que los diferentes países se posicionen mejor en el mercado internacional.

\section{BIBLIOGRAFÍA}

CASTILLO, J. (2007): «El futuro del Patrimonio Histórico: la patrimonialización del hombre» en E-RPH. Revista Electrónica de Patrimonio Histórico, n ${ }^{\circ} 1,18$ de julio de 2012. Disponible en hhtp://www.revistadepatrimonio.es

CEJUDO E. y CASTILLO, J. (2010): «La Vega de Granada. La construcción patrimonial de un espacio agrario» en Los regadíos históricos españoles. Paisajes culturales, paisajes sostenibles (Hermosilla, J., Ed). Madrid, MARM.

CLEERE, H., (2004): «World Heritage Vineyard Landscapes». World Heritage Review, n ${ }^{\circ}$ $35,10-19$.

ERICKSON, C.L. (2003): «Agricultural landscapes as World Heritage: Raised field agriculture in Bolivia and Peru» en Managing change: sustainable approaches to the conservation of the built environment. 4th US/ICOMOS International Symposium, Los Angeles, April 2001 (ICOMOS USA ed.). Los Angeles, GCI, 181-204.

ICOMOS (2004): Les paysages culturels viticoles. Etude thématique dans le cadre de la Convention du Patrimoine Mondial de l'UNESCO. Paris, ICOMOS.

JOKILEHTO, J. et. al. (2005): The World Heritage List. Filling the Gaps -an Action Plan for the Future. Paris, ICOMOS.

LALANA J.L. (2010): «Las zonas de amortiguamiento» en Documentos Centro Ciudades Patrimonio Mundial, $\mathrm{n}^{\circ}$ 01, 15 de mayo de 2012. Disponible en http://www.ccpm.es

MARTIN, O. y PIATTI, G. (eds.) (2008): World Heritage and Buffer Zones. International Expert Meeting on World Heritage and Buffer Zones, Davos, Switzerland 11 - 14 March 2008. Paris, UNESCO World Heritage Centre.

MARTÍNEZ, C. (2010): «The International Day for Monuments and Sites. Theme for $2010-$ «The Heritage of Agriculture» en ICOMOS International Secretariat e-news, $\mathrm{n}^{\circ}$ 54, 18 de abril de 2011. Disponible en http://www.international.icomos.org/18thapril/index.html

MARTÍNEZ, C. (2011): El patrimonio cultural: tendencias y proyecciones sociales y económicas. Estudio internacional y comparado del significado y uso del patrimonio ante los retos del siglo XXI. Madrid, Editorial Académica Española \& LAP LAMBERT Academic Publishing Gmbh \& Co.

SILVA, R. (2008): «Hacia una valoración patrimonial de la agricultura» en Scripta Nova. Revista Electrónica de Geografía y Ciencias Sociales, vol.XII, n 275, 21 de julio de 2012. Disponible en htpp://www.ub.es/geocrit/sn/sn-275.htm

UNESCO (2001): World Heritage Thematic Expert Meeting on Vineyard Cultural Landscapes, Tokai (Hungary), 11-14 July 2001 [online]. Disponible en www.whc.unesco.org/ en/culturallandscape/ [consulta 15 de mayo de 2011]. 
UNESCO (2007): Thematic meeting of experts on the agro-pastoral cultural landscapes in the Mediterranean, Meyrueis, Lozère (France), 20-22 September 2007 [online]. Disponible en www.whc.unesco.org/en/culturallandscape/[Consulta 15 de mayo de 2011].

VAN OLST, E.L. (1996): «Towards an integral documentation of agricultural vernacular architecture» en 11th ICOMOS General Assembly and International symposium: The heritage and social changes - symposium papers, Sofia (Bulgaria), 1996. Sofia, BNC/ ICOMOS, 642-644.

VERDUGO, J. (2005): «El territorio como fundamento de una nueva retórica de los bienes culturales». PH Boletín del Instituto Andaluz del Patrimonio Histórico, nº 53, 94-105. 